\title{
Teachers' experiences of supporting learners with attention-deficit hyperactivity disorder: Lessons for professional development of teachers
}

\begin{tabular}{|c|c|}
\hline \multicolumn{2}{|c|}{$\begin{array}{l}\text { Authors: } \\
\text { Simone Braude } \\
\text { Veronica Dwarika }^{1}\end{array}$} \\
\hline \multicolumn{2}{|c|}{$\begin{array}{l}\text { Affiliations: } \\
{ }^{1} \text { Department of Educational } \\
\text { Psychology, Faculty of } \\
\text { Education, University of } \\
\text { Johannesburg, Johannesburg, } \\
\text { South Africa }\end{array}$} \\
\hline \multicolumn{2}{|c|}{$\begin{array}{l}\text { Corresponding author: } \\
\text { Veronica Dwarika, } \\
\text { veronicam@uj.ac.za }\end{array}$} \\
\hline \multicolumn{2}{|c|}{$\begin{array}{l}\text { Dates: } \\
\text { Received: } 07 \text { Feb. } 2020 \\
\text { Accepted: } 10 \text { Sept. } 2020 \\
\text { Published: } 09 \text { Dec. } 2020\end{array}$} \\
\hline \multicolumn{2}{|c|}{$\begin{array}{l}\text { How to cite this article: } \\
\text { Dwarika, V. \& Braude, S., } \\
2020 \text {, 'Teachers' experiences } \\
\text { of supporting learners with } \\
\text { attention-deficit hyperactivity } \\
\text { disorder: Lessons for } \\
\text { professional development } \\
\text { of teachers', South African } \\
\text { Journal of Childhood } \\
\text { Education } 10(1) \text {, a843. } \\
\text { https://doi.org/10.4102/ } \\
\text { sajce.v10i1.843 }\end{array}$} \\
\hline \multicolumn{2}{|c|}{$\begin{array}{l}\text { Copyright: } \\
\text { (C) 2020. The Authors. } \\
\text { Licensee: AOSIS. This v } \\
\text { is licensed under the } \\
\text { Creative Commons } \\
\text { Attribution License. }\end{array}$} \\
\hline \multicolumn{2}{|l|}{ Read online: } \\
\hline 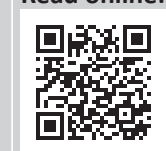 & $\begin{array}{l}\text { Scan this QR } \\
\text { code with your } \\
\text { smart phone or } \\
\text { mobile device } \\
\text { to read online. }\end{array}$ \\
\hline
\end{tabular}

Background: Inclusion policies require that learners with ADHD be taught in mainstream schools. For inclusion to be effective, the school personnel who are most responsible for its success must be responsive to the demands of educating learners by practicing values, beliefs, pedagogical applications, as well as assessment practices that support the needs of diverse learners within their classrooms. Such support necessitates a look at how teachers view learners with ADHD and how such views articulate into practices of support.

Aim: The study aimed to provide a description of teachers understanding of ADHD, and their experiences of supporting learners with ADHD to provide a lens for lessons that can be drawn for teacher professional development.

Setting: The study is set within an interpretivist paradigm and utilises a generic qualitative research design.

Methods: Qualitative data were collected through individual interviews with seven teachers each representing a grade from 1-7.

Results: Teachers' understanding of ADHD appeared to be limited. The stigma of ADHD creates a reluctance from caregivers towards pharmacological treatment. Professional development in strategies to support learners with ADHD, are deemed useful if, they are relevant and appropriate within the systemic context of their mainstream classrooms.

Conclusion: The professional development of teachers with the understanding, skills and knowledge to support learners with ADHD is advocated for. A collaborative consultation model for the growth of evidence-based school interventions for learners with ADHD is supported.

Keywords: Attention Deficit Hyperactivity Disorder (ADHD), inclusion professional development.

\section{Introduction}

Attention-deficit hyperactivity disorder (ADHD) continues to receive increasingly notable attention in the public, scientific and clinical arenas. Attention-deficit hyperactivity disorder contributes to impairments in personal, social and academic functioning (American Psychiatric Association [APA] 2013). Attention-deficit hyperactivity disorder is the most predominant neurological developmental disorder affecting between $2.0 \%$ and $16.0 \%$ of children (Schoeman \& De Klerk 2017).

\section{Scientific value}

Children with ADHD are considered to be learners with special educational needs (LSEN). Given that inclusion policies require that learners with ADHD be taught in mainstream schools, it can be accepted that teachers are daily expected to work with learners that present with ADHD symptoms of inattention, hyperactivity and impulsivity. Teachers are therefore in a distinctive position to provide insights on their experiences of supporting learners with ADHD, and to help us understand what they may need to support learners with ADHD more effectively. There is a continued need for greater understanding of teacher professional development needs when working with LSEN to ensure that inclusive education is embraced and pursued by teachers (Ntombela \& Raymond 2013). 


\section{Conceptual framework}

The philosophy of inclusive education underpins this study. This philosophy has emerged as an important aspect of international discussion and is central to educational policies in both developed and developing countries. Inclusive education focuses on how best to respond to learners who experience difficulties in school (Engelbrecht et al. 1999; Engelbrecht \& Green 2007). In South Africa, there is an imperative for education providers to work towards a system of education that is responsive to the various and diverse needs of its learners. This call emanates from the Salamanca statement (UNESCO 1994), which affirms the commitment to education for all. The UNESCO (1994) proclamation emphasised that regular schools with an inclusive orientation were the most effective means of combating discriminatory attitudes, welcoming communities, building an inclusive society and achieving education for all. South Africa participates enthusiastically in this growing international and local discourse on inclusive practices. The promulgation of Education White Paper 6: Special Needs Education: Building an Inclusive Education and Training System (DoE 2001) speaks to South Africa's response to the call for an inclusive education system. Inclusive education is described as being concerned with the development of an inclusive and humane society. White Paper 6 defines such a progressive system of education as one that makes determined efforts to develop learners' strengths and to provide opportunities for learners to actively and critically engage in the processes of learning within their school environments. Within White Paper 6 , inclusive education practices are considered critical and imperative for educational transformation within the inclusive education agenda.

A substantial requirement for inclusive practice, then, is what Walton (2018) describes as the process of expanding access and involvement and decreasing exclusionary pressures in all aspects of school life. Included in this emancipatory process of access and participation is the need for the identification and adjustment or modification of all attitudes, behaviours, teaching environments, teaching methodologies and curricula that do not meet the needs of all learners. Thus, within this model of inclusive education, it is considered the child's right to belong to the local mainstream school system. To ensure that policies of equal opportunity are practised. Ntombela and Raymond (2013) describe such a focused emphasis on an inclusive education system as being rooted in the international human rights movement. The aim of the international human rights movement is to apply democratic principles and social justice constructs to shape schools and the school experiences of all learners.

The philosophy underpinning inclusive education is the notion that every child can learn as articulated in White Paper 6 (DoE 2001). However, according to Engelbrecht and Green (2007), the values and beliefs of this philosophy pose a significant challenge to teachers and school communities. This challenge is to critically reflect upon, assess and develop values and beliefs as well as new instructional, learning and assessment practices that complement inclusive practice. Such dramatic systemic change will demand the involvement of all the stakeholders within the school system: the staff, school governing bodies, relevant support services, parents and children. The need for adequate support services to provide education has resultantly become a constitutional imperative in South Africa and abroad. Hargreaves (1994) acknowledges that there is no denying that the teacher is the ultimate key to educational change. He emphasises that 'it is what teachers think, what teachers believe and what teachers do at the level of the classroom that ultimately shapes the kind of learning that young people get' (p. 1). For inclusion to be effective, the school personnel who are most responsible for its success must be responsive to the demands of educating learners by practising values, beliefs, pedagogical applications and assessment practices that support the needs of diverse learners within their classrooms. Such support will also necessitate a further look at how teachers view learners with ADHD and how such views articulate into practices of support. Insight into teachers' experiences of supporting learners with ADHD provides guidelines for understanding professional development needs of teachers in finding ways to support learners with ADHD more effectively.

\section{Research method and design}

This study was situated within the qualitative interpretive research paradigm built on the premise that reality has multiple layers is complex and that one phenomenon can have many interpretations (Lincoln \& Guba 1985; Merriam 2009; Strauss \& Corbin 1998). This study determined teachers' subjective opinions, their perspectives, feelings and attitudes about ADHD, and their experiences in supporting learners with ADHD within their school context. The explorative nature of the study (Strauss \& Corbin 1998) allowed for new insights into and comprehension of the teachers' understanding and experiences of ADHD. The purpose of the study was to enhance the understanding of the support needs of teachers to more effectively include learners with ADHD in the classrooms and for directing professional development of primary school teachers.

\section{Setting of the study}

This study formed part of a wider study that spanned four of the country's 11 provinces: the Eastern Cape, Northern Cape, Mpumalanga and Gauteng. The wider study was a collaboration between the Department of Higher Education and Training (DHET) and the European Union (EU) focused on Teacher Education for Special Needs Education. The purposively selected schools identified by the provincial education departments were schools that showcased best practices in relation to support of learners with learning challenges. Selected schools included special schools, mainstream schools and mainstream schools with support classes. The research site reported on in this article is part of the latter category of selected schools. 
Situated in an affluent suburban area, the school site within this study is well resourced with multiple systems to support learners with special needs. The school is open to approximately 1000 learners, with a staff compliment of 56 educators, 13 grade assistants and five members of a multidisciplinary team which include psychologists, therapists and intern psychologists. The schools LSEN class supports approximately 15 learners.

Whilst all teachers were invited, there were seven teachers who volunteered to participate in the study. Seven teachers each represented one grade (1-7). Interviewing representative teachers with the most insight (Merriam 2009) facilitated understanding of the different perspectives and experiences of support in each grade and phase of learning. They were able to share their own experiences and those of the groups they represented.

\section{Data collection}

This study utilised semi-structured interviews guided by open-ended questions planned around a set of focused areas or guiding issues (Denscombe 2010; Glesne 2011; Merriam 2009). The guiding questions assisted to keep the target questions in mind whilst affording a level of flexibility for respondents to discuss aspects regarded as important that may have not been expected by the researcher (Braun \& Clarke 2014). The interviews were conducted over a 3-week period at a time convenient for the participants and lasted between 30 and $50 \mathrm{~min}$. The time frame allowed for general areas of discussion on inclusion, guided by questions that assisted in centring the discussion, thereby developing exploratory explanations and working the focused areas of supporting learners with ADHD into the conversation (Peel 2020).

\section{Data analysis}

The qualitative analysis undertaken in this study is based on Miles, Huberman and Saldaña (2014) interactive model of content thematic analysis. The three main components of data collection, data reduction and data display were directed at drawing out the relationships amongst participants social realities, based on regularities and sequences that linked these experiences (Punch 2009).

Credibility and confirmability were established by means of triangulation of the interviews from the various representative participants (Shenton 2004). Here each interview was compared to the rest of the interviews. Thus, seven interviews from the different participants were compared to safeguard that the findings matched the participants' views and realities and not those of the researcher (Merriam 2009). Although complete reliability is not possible within qualitative research, Denscombe suggests that a way to counter this is to defer to using the term 'dependability'. This refers to the researcher's demonstration that the research reflects 'procedures and decisions that other researchers can see and evaluate in terms of how far they constitute reputable procedures and reasonable decisions' (2010:300).

\section{Ethical consideration}

Ethical approval for the study was granted by the Ethics Committee of the Faculty of Education at the University of Johannesburg (ethical clearance number SEM 2019-083). This committee is registered at the Human Sciences Research Council. Permission to conduct the study was also obtained from the Gauteng Department of Education. All other ethical protocols were followed, including informed consent that was signed by each participant. Pseudonyms were used in the write-up of the study to protect the identities of the participants.

\section{Results and discussion}

The results and discussion thereof explicated as follows: firstly afford a description of teachers' understanding of ADHD, followed by their expressed experiences of supporting learners with ADHD. Finally, these two aspects of the discussion are drawn together to provide a lens on lessons that can be drawn for teacher professional development.

\section{Teachers' understanding of attention-deficit hyperactivity disorder}

Teachers' perceptions, attitude, knowledge and understanding of the disorder are significantly important for successful school intervention; it is considered to be one of the most significant factors in building effective teacherstudent interactions (Mohammed 2018). The teachers' understanding of ADHD seemed to be limited specifically with regard to the identification of learners with ADHD. When asked if the teachers felt confident in screening, identifying, assessing and supporting learners with ADHD, common responses across the Grade 1-7 teacher participant interviews were 'I'm taking a bit of a gamble' (P4, Grade 2, female); 'it is tricky to properly identify' (P4, Grade 2, female) and '... we're not trained to actually identify that child (P6, 'Grade 4, female). The reasons attributed to the challenges with identification were linked to 'probably not enough training '(P7, Grade 5 and 6, female); and the structural challenge of working in large classes as expressed by 'bigger classes, big problem, big challenge so in a class of 40, no I don't feel equipped '(P7, Grade 5 and 6, female). Feeling illequipped resonates with Lasisi et al. (2017) and Mulholland, Cumming and Jung (2015) who indicate that a lack of knowledge leads to inaccurate information which has the potential to limit identification.

In contrast, the two members representing the School Based Support Team (SBST) expressed confidence in the identification of learners with ADHD due to having been to many ADHD courses and conferences. Mulholland et al. (2015) further highlight that teachers' knowledge of ADHD, will enhance interaction with learners who have ADHD and provide more accurate identification and diagnosis of learners presenting with ADHD. It also supports Mohammed's (2018) research which postulates knowledge and understanding of ADHD are significantly important for successful intervention. 
Understanding of ADHD impacts identification of the symptoms associated with ADHD. Lasisi et al. (2017) indicate that lack of knowledge about ADHD leads to inaccurate information about ADHD and potential failure to identify learners with ADHD who would benefit from support. The Diagnostic and Statistical Manual of Mental Disorders, 5th edition (DSM 5) (APA 2013) criteria for ADHD include aspects of inattention, hyperactivity and impulsivity. Inattention includes a failure to give close attention to detail; difficulties with sustaining attention, following instructions and organising tasks and activities; avoids, dislikes tasks that require mental effort; is easily distracted; is often forgetful and loses things needed for tasks; often seems to not listen when spoken to directly. Impulsivity and hyperactivity presents behaviourally as restlessness, excessive talking, blurting out answers, difficulty waiting for their turn, interrupting others, excessive fidgeting, such as tapping of hands and feet as well as running and climbing inappropriately. Symptoms such as inattention, impulsivity and hyperactivity are evident in a classroom setting, making teachers the first to identify and refer. These behaviours become noticeable, as classroom settings require behaviours that are opposite to behaviours expressed by learners with ADHD (Lasisi et al. 2017). Within this study, common learner behaviours that teachers were easily able to link to ADHD symptoms of inattention included difficulty sustaining attention, and difficulty completing tasks. The participants, however, also identified some behaviours that were not part of the DSM 5 criteria for ADHD, such as: 'inability to cooperate', 'not following the general behaviour of the class' and 'difficulty getting along with peers'. Denis (2012) suggests that teachers do not have the skills to distinguish the differences between misbehaviour and attention deficits. Understanding and identifying the symptoms of ADHD are essential as teachers are the first line of identification for learners with difficulties (DBE 2014), they are also the first to suggest a diagnosis (Ghanizadeh, Fallahi \& Akhondzadeh 2009). A lack of knowledge about ADHD leads to inaccurate information about ADHD and potential failure to identify learners with ADHD who would benefit from support (Lasisi et al. 2017).

To help them understand their learners better, participants reported that they would consult the learner's profile: 'so if you start to pick up with this problem'. The stigma reported by the participants was also linked to the aspect described above:

'You will then go back to the profile' (P1, Grade 3, female, 17 July 2019)

'I'll even go to the learner profile and see what they say in there' (P5, Grade 6, male, 29 July 2019)

'... so we do get notified if they are ADHD, it's in their profile' (P5, Grade 6, female)

There were some difficulties regarding the use of the profile to identify learners with ADHD. These included none of limited profile information as well as time constraints. These are evidenced by the following observations expressed by the participants: 'because you get so caught up in the madness, you don't have a chance to go through every single profile ' (P1, Grade 3, female, 17 July 2019); also 'often there is absolutely nothing in their profile' (P3, Grade 6 and 7, female, 05 August 2019).

Teachers' understanding of ADHD was also linked to their personal experiences. Some of these experiences related to themselves or siblings or extended family members and friends being diagnosed with ADHD. These interactions add to teacher's experiences and understanding of ADHD and impact the ways in which teachers perceive ADHD and support learners in their classrooms with ADHD; they also impact the way teachers engage with parents regarding ADHD (Al-Moghamsi \& Aljohani 2018).

Of the seven participants, three teachers relayed their personal experiences. All three expressed that those experiences assisted them in better understanding learners with ADHD. One participant disclosed that she herself had ADHD as a child, describing herself as 'I was an ADHD case' (P2, Grade 1, female, 18 July 2019). Her experience helped her to understand that food colourants were one of the reasons that led to her hyperactivity as a child. 'I was at the point that I was allergic to colourants ... it used to make me hyperactive'. This same participant indicated that her understanding of the role diet plays in ADHD, has helped her to support learners better: 'I don't allow sweets in my class, not even cool drink, no fizzy nothing, not even flavoured water'.

In relation to understanding the value of medication for learners with ADHD, another participant relayed her experience that her friend's child was prescribed Concerta, 'and he just refused to take it from Grade 11 and he dropped out in Grade 11' (P3, Grade 6 and 7, female, 22 July 2019). Within her teaching experience, she reported: 'I've had children that have been diagnosed and they are on medication and the parents just stop'. This participant considered medication in the support of ADHD was as necessary as she had seen first-hand the impact of non-compliance on the academic future of her friend's son. It is important, however, to note that although the use of medication to treat the symptoms of ADHD is one way to support learners, behavioural, social and academic classroom interventions are a necessary component in an attempt to fully include ADHD learners in a classroom setting (Lee \& Witruk 2016). The participant in this example did show an understanding of the value of a more holistic approach to support. She reflected that her advice to parents included:

'... get your child into aftercare, sit with them with homework, take them to the doctor, start the process of going to a neurologist, try change the diet, don't give him so much sugar, all of those things'. (P3, Grade 6 and 7, female)

A third participant with the experience of his son being diagnosed ADHD, shared the social challenges of living with a child with ADHD: 'it's not always easy to get on with a child ... they show anger, disruptive behaviour a lot of times as well ... must just have patience with this child'. At least $22 \%$ of children with ADHD are considered socially disabled 
(Bühler et al. 2011). According to Villodas et al. (2014), parent and teacher interactions with children who have ADHD often result in constant reprimanding which negatively affects these relationships. Experiences of the social challenges associated with the symptoms have an impact on intervention and inclusion of learners with ADHD.

\section{Teachers' experiences of working with learners with attention-deficit hyperactivity disorder}

The range of years of participants' teaching experience was between 4 and 39 years, three participants had more than 25 years of experience with four participants with less than 10 years' experience. Years of teaching experience allows for the growth of knowledge that is gained in the classroom rather than from training. Anderson et al. (2012) and Lee and Witruk (2016) found that teachers with more experience in terms of teaching years tend to have more favourable attitudes towards learners with ADHD than those who have less or no experience. The participants in this study, however, used several unfavourable descriptors for learners with ADHD, including 'difficult', 'frustrating', 'bad', 'nightmare' and 'anxiety'. These perceptions influence how teachers approach learners with ADHD and how they tend to support them (Kos, Richdale \& Jackson 2004).

Systemic factors of large class sizes and curriculum demands were factors that played a major role in teachers' experiences of supporting learners with ADHD. Large class sizes of 40 learners are a barrier to learning in itself (Naude \& Meiers 2019). Participants shared their frustrations encapsulated in the following response by one participant:

'I feel like with the big sizes that we have I can't give them everything specifically they need. I feel like its very unfair to them. Just because I mean it's 40 that you are controlling at once needs constant hands-on. Now an ADHD child needs more, they need you there all the time'. (P2, Grade 1, female)

With regard to curriculum demands, one participant summed up the challenge: 'there's too much content to be taught ... so, an ADHD child ... is going to stay there and fall behind.' (P6, Grade 4, female)

\section{Teachers' experiences of support strategies for learners with attention-deficit hyperactivity disorder}

Some of the strategies used involved giving the learners extra time to complete work or seating them alone or limiting distractions for them. The research indicated that besides one intermediate phase teacher, the only teachers implementing these strategies are the foundation phase teachers. This finding suggests that there is more classroom support available to learners in the foundation phase than in the intermediate and senior phases. One of the more common strategies found was to allow learners to leave the classroom either to go to another teacher, the toilet or run to the field as a means of expending extra energy as indicated by four out of seven participants.
The use of repetition to remind learners about the instructions is an important strategy to use when supporting learners with ADHD. As attention is a challenge for learners with ADHD, repeating information helps learners with ADHD to identify instructions if they have lost concentration the first time it was explained (Ainsworth 2015). The data collected showed that only two of the participants used this as a strategy. This would suggest that learners, who find concentration and attention a challenge, miss out on instruction and content if teachers do not provide repetition.

Behavioural interventions are important when supporting learners with ADHD as a common symptom of the disorder is impulsivity (APA 2013). The study indicated that two of the participants use classroom rules that are visible to learners. One participant mentioned that a daily report is used; however, this is for behavioural issues and is not specific to learners with ADHD. None of the participants used the method of rewarding good behaviour; however, one participant mentioned that there is a merit dojo system which records learners' growth points and achievement. Accumulation of points offered the reward of certificates for favourable behaviour such as completing homework tasks, and demerits as punishment for undesirable behaviours such as incomplete tasks.

Mavuso (2014) identifies that South African teachers use extra lessons, extra work, differentiation of teaching styles, assessment and peer support as strategies in mainstream schools. These interventions are important when supporting learners with ADHD as they provide a form of repetition for learners who find concentration and attention difficult. Participants within the study highlighted the following strategies that were commonly used by them when supporting learners with ADHD: 'use of extra lessons, "extra support", "peer support" and "the use of differentiation when teaching and assessing learners"'.

Du Paul, Eckert and Vilardo (2012) recommend schoolbased interventions to support learners with ADHD. At the research site, a common school-based intervention to support learners with ADHD is the adherence to a strict diet for the Grade 1 learners. The Grade 1 learners are all required to eat a healthy lunch that includes no artificial sugars. This information is given to the parents at the beginning of the year at an information evening held by the teachers for the parents. This was confirmed by three participants representing Grade 1-3. The other wholeschool intervention at the research site included a parental support group for parents who have children with ADHD. This support group meets once a month where they share experiences and get feedback from specialists. The participants indicated that these meetings have been helpful to parents as they provide information as well as support. Unfortunately, there was not much data about the experiences of parents during these sessions as well as its effectiveness in supporting parents. 


\section{Teachers' experiences of collaboration with caregivers of learners with attention-deficit hyperactivity disorder}

Part of a teachers' responsibility as outlined in the DBE (2016) is communication, and this involves communication with relevant stakeholders such as other teachers, heads and parents. Teachers are expected to meet with caregivers to discuss progress of learners (DBE 2016). All seven participants mentioned requesting meetings with the caregivers of learners who presented with symptoms of ADHD. The purpose of such collaborations was twofold: to recommend an assessment of the learner take place to confirm diagnosis so that appropriate support could be afforded; as well as to follow up on with the caregivers whether recommendations following diagnosis were being adhered to. Participants reported that caregivers were reluctant to consider a diagnosis of ADHD or a suggested assessment from teachers. One participant explained that such reluctance was linked to caregiver denial that a challenge exists with their child: 'parents are very much in denial about their children's problems ... it's difficult to persuade parents to you know, have your child assessed' (P7, Grade 5 and 6, female). Denial and reluctance by the parents often result in a delayed active support or no support at all:

'Parents are ignoring you for the first three years, then they start listening to you in the fourth year (Grade 4, intermediate phase) and then often still nothing ever gets done.' (P3, Grade 6 and 7, female)

Such responses are considered typical of a grief response of caregivers of learners with ADHD (Godress et al. 2005). The majority of respondents confirmed that caregivers experienced sadness, disappointment and grief that their child may be having a learning challenge: 'no one wants to hear that their child has an issue, it's not a nice feeling' and that '... for the parents as well there can be sometimes feelings of disappointment ... we all think our children are perfect and parents don't want to hear negative news'. The stigma associated with ADHD was also evident amongst caregiver perceptions. When learners are identified as ADHD, there are social expectations of that label that will be imposed (Denis 2012). The stigma associated with ADHD often leads to negativity and stereotyping (Upadhyay et al. 2016). Common responses from parents were reported by participants as:

'Oh, my child is stupid ... does he need to go to a remedial school, what type of life will he have?; and "oh my child is dof" or "my child is a problem child"'. (P2, Grade 1, female)

The stigma reported by the participants was also linked to the aspect of medication or use of medication without regular monitoring. This included comments such as '... there's a whole stigma that's just attached to ADHD because they're not medicated correctly' (P6, Grade 4, female). Reporting on parents' experience of ADHD medication, one participant reported the parent observation as follows: '... when he takes the Ritalin, he becomes very quiet and lethargic and it changed his personality' (P3, Grade 6 and 7, female). Another participant shared: '... the mom explained it like a bit of a zombie' (P4, Grade 2, female). A common experience was described by another participant as: '... a lot of parents complain that it changes the children's mood'. The symptoms of ADHD can be managed with stimulant drugs such as methylphenidate and amphetamines (Ainsworth 2015). These drugs are either used alone or combined with other methods such as classroom and academic interventions and cognitive behavioural intervention strategies (Du Paul et al. 2012). According to Barkley (1997), an effective intervention process should, however, include psychoeducation about ADHD, behaviour management techniques, resources and medication.

It is possible that when difficulties are stigmatised, they result in the reluctance towards treatment (Canu et al. 2008). One participant suggested that: '... when parents are unwilling or not ready to accept the possibility of ADHD of the child, they may become unwilling to seek support for the child' (P4, Grade 2, female). The statement was also supported by another participant who indicated that parents needed to be told 'multiple times by different teachers before they start intervening'. There was, however, one participant who indicated that her experiences with caregivers of learners with ADHD, had been mostly positive: 'I've never had a parent come to me and say ... well no I disagree with you and you are pulling this out of a hat' (P6, Grade 4, female). This participant, however, reflected that caregiver willingness to act on teacher advice has been somewhat waning over the years of her experience: '... I just feel that over the years parents are just not involved' (P6, Grade 4, female).

\section{Teachers' experiences of their interactions with the School Based Support Team to support learners with attention-deficit hyperactivity disorder}

According to the DBE (2014) if teachers support plans are unsuccessful it is taken to the School Based Support Team (SBST), the SBST which the teacher will now form part of put in place other interventions to support the learner with ADHD. Only when these interventions are unsuccessful, will the SBST seek the help of the District Based Support Team (DBST). The role of the SBST implies that members of the SBST should have a sound knowledge in the screening, identification, assessment and support for at-risk learners including learners with ADHD. Every participant in the study mentioned that the school has a functioning SBST. And that there were active engagements with the SBST on a regular basis. Such engagements included: 'requests for assistance with screening learners for ADHD'; 'support for the development of interventions and individual learning plans for learners with $\mathrm{ADHD}^{\prime}$; and '... to facilitate a referral to specialists who can support a learner with ADHD'. Although all participants mentioned a functioning SBST, one participant reported that her collaboration was limited 
because '... I still don't believe that just by looking at a child you can say they are ADHD' (P4, Grade 2, female), suggesting that a clinical diagnosis was necessary before support and intervention could be arranged.

\section{Teachers' experiences of professional development related to attention-deficit hyperactivity disorder}

Professional development refers to systematic professional learning that results in changes to teacher knowledge and skills, and progress in student educational outcomes (Darling-Hammond, Hyler \& Gardner 2017). It is widely accepted that developing the expertise and knowledge of teachers is one of the most fundamental measures to increase student achievement (Smith, Preston \& Hay 2020). Teachers with ADHD training have higher levels of knowledge and fewer negative attitudes and misconceptions towards learners with ADHD as opposed to teachers who do not have prior training. Within this study, of the seven participants, all except one indicated that they had attended a professional development course on ADHD at some stage within their careers. Courses on ADHD included those offered by various organisations including school, and parent-teacher forums, as well as presentations offered by institutions. Some comments from respondents included the following: 'I have attended briefly, not here, but at my previous school'; another respondent indicated: 'I attended a course a Kempton park where they invited all the teachers in the area at the schools, but it was a dyslexia slash ADHD course'; Further response included: 'I attended a talk about ADHD that was given to the parents at the school'; and, '... I went to one of those courses that WITS holds... one of their ADHD courses ... but that was over a couple of years ago;' 'I attended a course on the types of medication you can use and how it affects the child and how to combine the diet of the child'.

The value received at these workshops or trainings that the respondents had attended, varied. Nel and Grosser (2016) indicate that teachers should be equipped with knowledge, skills, strategies and a positive attitude to enable them to manage inclusion. Some positive response reflected an improved understanding of learners with ADHD: '... it reinforces what you see in the child and now you can actually put in words well actually this is what's going on ...'; '... very helpful and I understood the child much better'; '... the strategies and the advice they gave on how to deal with a child like that in the classroom, that was very helpful'. Messiou et al. (2016) advocate that with an inclusive pedagogy, teachers will respond positively to the diversity of learners. Inclusive pedagogy helps develop and enrich learning (Engelbrecht et al. 2015).

The submission of Engelbrecht et al. (2015), that inclusion principles has not been adequately transferred into mainstream classroom, holds true for some participants views within this study. Participants reflected that the trainings 'seemed idealistic' because the strategies suggested could not be used effectively as '... there were just too many children'. The strategies for supporting learners with ADHD seemed 'unrealistic in a class of 40'. The use of jargon and medical terminology during the training was also challenging for respondents: 'the medical terms that they used, that isn't really helpful', suggesting these impacted the level of understanding and participation within the workshops.

Respondents also indicated that they were aware that continuous professional development in the understanding and supporting learners with ADHD was necessary. Respondents reflected that: 'training should be happening constantly because new research is coming up all the time' and '... training should be continuous'. Makoelle (2014) found that inclusion is understood differently by people, and this influences how it is practised.

\section{Lessons for continuous professional development of teachers}

The discussion here will draw on the findings reported in this article and will make a case for continued and focused professional development to support teachers in their work with learners with ADHD. Florian and Linklater (2010) established that teachers are often uncertain about how to respond to the challenges learners in their classrooms experience. This is a pressing dilemma as children with ADHD are in mainstream classrooms and are expected to be included in teaching and learning. Teachers' knowledge of and attitude towards the disorder of ADHD are critical. Pfiffner, Barkley and Du Paul (2006) emphasise that if teachers lack a

$[G]$ rasp of the nature, course, outcome, and causes of this disorder and misperceptions about appropriate therapies, attempting to establish behaviour management programs within that teacher's classroom will have little impact. (p. 549)

Conversely, a positive teacher-learner relationship, based on teacher understanding of the learner and the disorder, may improve academic and social functioning (Pfiffner et al. 2006).

Topkin, Roman and Mwaba (2015) found that there is a need for improving evidence-based strategies for South African teachers. Such strategies could help teachers overcome the common frustrations experienced when supporting learners with ADHD. Behavioural interventions, school-based interventions and classroom interventions need to mesh when supporting learners with ADHD (Ainsworth 2015; Mavuso 2014; Villodas et al. 2014). It is understood that ADHD is a lifetime disorder and the motivation of schoolbased interventions needs to be long-term. Such long-term interventions require individualised learner support plans (ILPs). These ILPs will necessitate continuous review, evaluation, adaptation and implementation across settings over the course of months and years that the leaner is in the classroom (Pfiffner et al. 2006). School-based interventions need to incorporate both proactive and reactive strategies to maximise learner behavioural change. Proactive strategies that prevent challenging behaviours from occurring include, 
for example, maintaining consistency in the establishment of clear rules and routines to support learner behaviour and learning progress (Lewis et al. 2010). Learners with AHDH will benefit from fewer rules, and posting of these positively framed classroom rules in closer proximity to them like on an index card on their desk (Du Paul et al. 2012). The literature highlights that research on the value of classroom rules spans more than 40 years and that classroom rules, both organisational rules and instructional rules, form one of the basic behavioural strategies in classroom management (Gable et al. 2009).

Reactive strategies of positive reinforcement following a target behaviour support behavioural change in all learners, including learners with ADHD (Pfiffner et al. 2006). Positive reinforcement strategies include the use of praise, token economy and rewards. These are used by teachers to recognise and reward desirable activities or outcomes (Byron \& Khazanchi 2012). Praising learners for behaviours that they are learning to control (e.g. for paying attention and for working effectively in a group) increases the likelihood of intrinsic motivation and achievement (Howell et al. 2014). Burnett and Mandel (2010) report that primary school learners had positive reactions to teachers' use of verbal praise, and that teachers' verbal praise made them feel supported. Another study by Marchant and Anderson (2012) reports that teachers believed praise improved relationships and motivated learners to learn. When one considers these proactive and reactive strategies approach as best practice strategies, the support of learners within the mainstream classroom could from the perspective of the teacher, become less idealistic and more attainable even in large class sizes.

Training on antecedent-based strategies is valuable in supporting learners with ADHD (Du Paul et al. 2012). These strategies can include a decrease in the length of task as well as a modification of the content thereof, to reducing learner off task behaviour. Providing learners with the opportunity to choose from a set of tasks that all test the same academic skill can also serve to increase task engagement and lower learner disruptive behaviours (Dunlap et al. 2009) Antecedent-based strategies are further enhanced when coupled with the teacher's praise for learners' task completion (Du Paul et al. 2012)

Professional development training should also include aspects of accommodations for academic support for learners with ADHD. Such accommodations involve supplemented notes, separate venues and additional time for tests and examinations (Ainsworth 2015). For learners who are on medication for ADHD, the types of accommodations received should be carefully evaluated, as the medication diminishes or removes the barrier of not being able to focus. In this case, an accommodation would place the learner at an advantage as the learner would be receiving accommodations such as extra time and a separate venue, rather than promoting the ideas espoused by inclusion (Ainsworth 2015). Whilst the scope of this article does not allow for an in-depth discussion on psychopharmacology for learners with ADHD, it is important to mention that a significant amount of work has been put into psychopharmacology for 'improving delivery systems, increasing the duration of effect, incorporating mixed (rising) dose intensities across the day, and better targeting the diverse needs of learners with ADHD' (Pfiffner et al. 2006:548). It would be valuable if teacher training on ADHD could also include how to draw attention to designing behavioural support to individual learner demands; how to increase the effects thereof across time and situations; and how to step up the implementation of effective interventions by teachers within their classrooms.

An essential consideration for increasing the effectiveness of school-based support strategies for learners with ADHD is the interconnected relationship between home and school. The importance of the role of parents in relation to homeschool partnerships has been recognised in legislation and policies, including the South African Schools Act (Republic of South Africa 1996) and Education White Paper 6 (DoE 2001). There is strong documented evidence to support the possible benefits to learners, parents and teachers of parental partnership and collaboration with schools (Westergard 2013; Yssel et al. 2007). From an ecological perspective, the supportive collaborative relationship between the home and school microsystems is indicative of what Mampane and Bouwer (2011) describe as the development of protective factors that support the child's learning and development. Pirchio et al. (2013) also emphasise the importance of parental involvement in a child's schooling as it is associated with positive outcomes of fewer behavioural problems and better social conduct. Pfiffner et al. (2006) highlight that in situations where 'both teacher and parents are knowledgeable about ADHD, have realistic goals, and are motivated to work with ADHD, effective collaborations develop easily' (p. 552). How to engage parents effectively taking into consideration power differentials and literacy levels should not be negated from teacher professional development. There is a significant connection between social class and the effectiveness of parents and caregivers in dealing with teachers, and this connection is powerfully rooted in cultural capital (Reay 2004). The strategy of initiating collaboration with parents is valuable particularly where parents may play a passive role or lack the power to freely engage in the process of collaboration (Freeman 2010).

With regard to the duration of professional development, usually single session or one day in-service presentations, whilst useful for imparting information about ADHD, is usually not sufficient for training teachers how to implement support programmes (Du Paul et al. 2012). School-based training can be effective, however, if applied within the collaborative consultation model (Pfiffner et al. 2006). The collaborative consultation model should constitute a multidisciplinary team, including teachers, members of the SBST, members of the DBST and, where possible, psychologist and other relevant role player including parents. This model assists in supporting teachers in a systematic manner to 
evaluate learner needs, plan, implement and monitor learner support interventions (Du Paul et al. 2012). A further consideration for training teachers in the support of learners with ADHD is the degree to which these strategies are regarded as suitable and appropriate by teachers. Studies suggest that teachers 'prefer positive over negative consequences, behavioural interventions with medication over medication alone, and time-efficient (e.g. home-school daily report cards) over time consuming (e.g. response cost) interventions' (Pfiffner et al. 2006:551).

The main aim of teacher professional development is to develop and enhance basic knowledge amongst teachers about the nature, causes, course and treatments for ADHD. A second aim of such interventions is to build home and school collaboration, to generate a more consistent, and effective plan in the support of learners with ADHD that includes the major caregivers. Both of these goals lead to the commitment to psychoeducational programmes for ADHD, which strengthens the academic and social effectiveness of children with ADHD in the school setting (Du Paul et al. 2012)

\section{Limitations of the study}

The study was localised and limited in scope. Whilst the findings do not represent the widespread experiences of teachers supporting learners with ADHD, it does serve to add to the body of knowledge within the field of inclusive education and ADHD. Participants within the study were pressed for time given their extra and co-curricular activities. Whilst the interviews were pre-arranged at a time suitable with the participants, not all participants were able to provide the researcher with the full length of time to allow for probing to gauge greater depth of understanding. The responses therefore from participants were somewhat limited because of time constraints.

\section{Conclusion}

The study provided insight into teachers' experiences of supporting learners with ADHD. This study suggests that factors such as attitudes towards ADHD, teachers' experiences of supporting learners with ADHD and teachers' experiences of home-school collaborations with the caregivers of the same learners need to be carefully considered when supporting the professional development needs of teachers. This study supports the need for professional development of teachers within a collaborative consultation model for the growth of evidence-based school interventions for learners with ADHD.

\section{Acknowledgements}

Ms Kerri Dimant is acknowledged for her work in providing the secondary data for this research.

\section{Competing interests}

The authors declare that no competing interests exist.

\section{Authors' contributions}

The first author (S.B.) was the researcher for the study. The second author (V.D.) was the research supervisor for the study.

\section{Funding information}

Research funding was obtained from the Teacher Education for Special Needs Education (TESNE) project.

\section{Data availability statement}

Data collected in this study are available for sharing on request.

\section{Disclaimer}

The views and opinions expressed in this article are those of the authors and do not necessarily reflect the official policy or position of any affiliated agency of the authors.

\section{References}

Ainsworth, R., 2015, 'Attention deficit hyperactivity disorder: Excuse or epidemic?', The Journal of Law and Education 44(3), 453-462.

Al-Moghamsi, E. \& Aljohani, A., 2018, 'Elementary school teachers' knowledge of attention deficit/hyperactivity disorder', Journal of Family Medicine \& Primary Care 7(5), 907-915.

American Psychiatric Association (APA), 2013, Diagnostic and statistical manual of mental disorders, 5th edn.. American Psychiatric Association, Washington, DC.

Anderson, D.L., Watt, S.E., Noble, W. \& Shanley, D.C., 2012, 'Knowledge of attention deficit hyperactivity disorder (ADHD) and attitudes toward teaching children with ADHD: The role of teaching experience', Psychology in the Schools 49(6), 511-525. https://doi.org/10.1002/pits.21617

Barkley, R.A., 1997, 'Behavioral inhibition, sustained attention, and executive functions', Psychological Bulletin 121(1), 65-94. https://doi.org/10.1037/00332909.121.1.65

Braun, V. \& Clarke, V., 2014, 'What can thematic analysis offer health and wellbeing researchers?', International Journal of Qualitative Studies on Health and Wellbeing 9(1), a26152. https://doi.org/10.3402/qhw.v9.26152

Bühler, E., Bachmann, C., Goyert, H., Heinzel-Gutenbrunner, M. \& Kamp-Becker, I., 2011, 'Differential diagnosis of autism spectrum disorder and attention deficit hyperactivity disorder by means of inhibitory control and "Theory of mind"', Journal of Autism and Developmental Disorders 41(12), 1718-1726. https://doi. org/10.1007/s10803-011-1205-1

Burnett, P.C. \& Mandel, V., 2010, 'Praise and feedback in the primary classroom: Teachers' and students' perspectives', Australian Journal of Educational \& Developmental Psychology 10, 145-154.

Byron, K. \& Khazanchi, S., 2012, 'Rewards and creative performance: A meta-analytic test of theoretically derived hypotheses', American Psychological Association 138(4), 809-830. https://doi.org/10.1037/a0027652

Canu, W.H., Newman, M.L., Morrow, T.L. \& Pope, D.L.W., 2008, 'Social appraisal of adult ADHD', Journal of Attention Disorders 11(6), 700-710. https://doi. org/10.1177/1087054707305090

Darling-Hammond, L., Hyler, M.E. \& Gardner, M., 2017, Effective teacher professional development, Learning Policy Institute, Palo Alto, CA.

Denis, C.M., 2012, 'Attention deficit hyperactivity disorder and Bronfenbrenner's ecology of human development', Doctoral thesis, Georgia Southern University, Statesboro, Georgia.

Denscombe, M., 2010, The Good research guide: For small scale social research projects, Open University Press, London.

Department of Basic Education (DBE), 2014, Policy on screening, identification, assessment and support, Government Printers, Pretoria.

Department of Basic Education (DBE), 2016, Personnel administrative measures, Government Printers, Pretoria.

Department of Education (DoE), 2001, Education white paper 6: Special needs education: Building an inclusive education and training system, Government Printers, Pretoria.

Du Paul, G.J., Eckert, T.L. \& Vilardo, B., 2012, 'The effects of school-based interventions for attention deficit hyperactivity disorder: A meta-analysis 1996-2010', School Psychology Review 41(4), 387-412. https://doi.org/10.1080/02796015.2012.120 87496 
Dunlap, G., Sailor, W., Horner, R. \& Sugai, G., 2009, Overview and history of positive behavior support, in W. Sailor, G. Dunlap, G. Sugai \& R. Horner (eds.), Handbook of positive behavior support, pp. 3-16, Springer, Boston, MA. Engelbrecht, P. \& Gositive behavior support, $\mathrm{pp}$. (eds.), 2007, Responding to the challenges of inclusive education in Green, L. (eds.), 2007, Responding to the challen
Southern Africa, Van Schaik Publishers, Pretoria.

Engelbrecht, P. \& Green, L. (eds.), 2007, Responding to the challenges of inclusive education in Southern Africa, Van Schaik Publishers, Pretoria

Engelbrecht, P., Green, L., Naicker, S. \& Engelbrecht, L. (eds.), 1999, Inclusive education in action in South Africa, Van Schaik Publishers, Pretoria.

Engelbrecht, P., Nel, M., Nel, N. \& Tlale, D., 2015, 'Enacting understanding of inclusion in complex contexts: Classroom practices of South African teachers', South Africa Journal of Education 35(3), 1-10. https://doi.org/10.15700/saje.v35n3a1074

Florian, L. \& Linklater, H., 2010, 'Preparing teachers for inclusive education: Using inclusive pedagogy to enhance teaching and learning for all', Cambridge Journal of Education 40(4), 369-386. https://doi.org/10.1080/0305764X.2010.526588

Freeman, M., 2010, 'Knowledge is acting: Working-class parents intentional acts of positioning within the discursive practice of involvement', International Journa of Qualitative Studies in Education 23(2), 181-198. https://doi.org/10.1080/ 09518390903081629

Gable, A.R., Hester, P.H., Rock, M.L. \& Hughes, K.G., 2009, 'Back to basics: Rules, praise, ignoring, and reprimands revisited', Intervention in School and Clinic 44(4), 195-205. https://doi.org/10.1177/1053451208328831

Ghanizadeh, A., Fallahi, M. \& Akhondzadeh, S., 2009, 'Disclosure of attention deficit hyperactivity disorder and its effect on rejection of students by teachers', Iranian Journal of Medical Sciences 34(4), 259-264.

Glesne, C., 2011, Becoming qualitative researchers: An introduction, 4th edn., Pearson Prentice Hall, Boston, MA.

Godress, J., Ozgul, S., Owen, C. \& Foley-Evans, L., 2005, 'Grief experiences of parents whose children suffer from mental illness', Australian and New Zealand Journal of Psychiatry 39(1), 88-94. https://doi.org/10.1080/j.1440-1614.2005.01518.x

Hargreaves, A., 1994, Changing teachers, changing times, Redwood Books, London.

Kos, J.M., Richdale, A.L. \& Jackson, M.S., 2004, 'Knowledge about attention-deficit/ hyperactivity disorder: A comparison of in-service and preservice teachers', Psychology in the Schools 41(5), 517-526. https://doi.org/10.1002/pits.10178

Lasisi, D., Ani, C., Lasebikan, V., Sheikh, L. \& Omigbodun, O., 2017, 'Effect of attentiondeficit-hyperactivity-disorder training program on the knowledge and attitudes of primary school teachers in Kaduna, North West Nigeria' Child and Adolescen Psychiatry and Mental Health 11, article 15, 1-8. https://doi.org/10.1186/ s13034-017-0153-8

Lee, Y. \& Witruk, E., 2016, 'Teachers' knowledge, perceived teaching efficacy, and attitudes regarding students with ADHD: A cross-cultural comparison of teachers in South Korea and Germany', Health Psychology Report 2(2), 103-115. https:// doi.org/10.5114/hpr.2016.58383

Lewis, T.J., Jones, S.E.L., Horner, R.H. \& Sugai, G., 2010, 'School-wide positive behavior support and students with emotional behavioral disorder: Implications for preventions, identification and intervention', Exceptionality: Special Education preventions, identification and intervention', Exceptionality: Special
Journal 18(2), 82-93. https://doi.org/10.1080/09362831003673168

Lincoln, Y.S. \& Guba, E.G., 1985, Naturalistic inquiry (vol. 75), Sage, Thousand Oaks, CA.

Makoelle, T.M., 2014, 'Pedagogy of inclusion: A quest for inclusive teaching and learning', Mediterranean Journal of Social Sciences 5(20), 1259-1267. https://doi. org/10.5901/mjss.2014.v5n20p1259

Mampane, R. \& Bouwer, C., 2011, 'The influence of township schools on the resilience of their learners', South African Journal of Education 31(1), 114-126. https://doi. org/10.15700/saje.v31n1a408

Marchant, M. \& Anderson, D.H., 2012, 'Improving social and academic outcomes for all learners through the use of teacher praise', Sage Journal 21(3), 22-28. https:// doi.org/10.1177/107429561202100305

Mavuso, M.F., 2014, 'Strategies for facilitating learning support processes: What can teachers do to support learners with specific learning difficulties?', Mediterranean tournal of Social Sciences 5(2), 455-461. https://doi.org/10.5901/mjss.2014. vournal of

Merriam, S.B., 2009, Qualitative research: A guide to design and implementation, rev. and expanded edn., Jossey-Bass, San Francisco, CA.

Messiou, K., Ainscow, M., Echeita, G., Goldrick, S., Hope, M., Paes, I. et al., 2016 , 'Learning from differences: A strategy for teacher development in respect to student diversity', School Effectiveness and School Improvement 27(1), 45-61. https://doi.org/10.1080/09243453.2014.966726

Miles, M.B., Huberman, A.M. \& Saldaña, J., 2014, Qualitative data analysis: A methods sourcebook, 3rd edn., Sage, Thousand Oaks, CA.

Mohammed, F., 2018, 'Effects of a tailored incredible years teacher classroom management programme on on-task behaviour of school children with ADHD in Addis Ababa', Journal of International Special Needs Education 21(1), 1-13. https://doi.org/10.9782/15-00055R2
Mulholland, S.M., Cumming, T.M. \& Jung, J.Y., 2015, 'Teacher attitudes towards students who exhibit ADHD-type behaviours' Australasian Journal of Special Education 39(1), 15-36. https://doi.org/10.1017/jse.2014.18

Naude, M. \& Meier, C., 2019, 'Elements of the physical learning environment that impact on the teaching and learning in South African grade 1 classrooms', South African Journal of Education 39(1), article 1342, 11 pages. https://doi. African Journal of Education
$\mathrm{org} / 10.15700 /$ saje.v39n1a1342

Nel, M. \& Grosser, M.M., 2016, 'An appreciation of learning disabilities in the South African context', Learning Disabilities: A Contemporary Journal 14(1), 79-92.

Ntombela, S. \& Raymond, E., 2013, 'Inclusive education in South Africa and globally', in C.F. Pienaar \& E.B. Raymond (eds.), Making inclusive education work in classrooms, pp. 2-17, Pearson Education South Africa, Cape Town.

Peel, K., 2020, 'A beginners guide to applied educational research using thematic analysis', Practical Assessment, Research and Evaluation 25(1), 2.

Pfiffner, L.J., Barkley, J.A. \& Du Paul, G.J., 2006, 'Treatment of ADHD in school settings', in R.A. Barkley (ed.), Attention deficit hyperactivity disorder: A handbook for diagnosis and treatment, pp. 547-589, The Guilford Press, London.

Pirchio, S., Passiatore, Y., Tritrini, C. \& Taeschner, T., 2013, 'The role of the relationship between parents and educators for child behavior and wellbeing', International Journal about Parents in Education 7(2), 145-155.

Punch, K.F., 2009, Introduction to research methods in education, Sage, London.

Reay, D., 2004, 'Education and cultural capital: The implications of changing trends in education policies', Cultural Trends 13(2), 73-86. https://doi.org/10.1080/ 0954896042000267161

Republic of South Africa (RSA), 1996, South African Schools Act 84 of 1996, Republic of South Africa Government, Pretoria.

Schoeman, R. \& De Klerk, M., 2017, 'Adult attention-deficit hyperactivity disorder: A database analysis of South African private health insurance', South African Journal of Psychiatry 23, a1010. https://doi.org/10.4102/sajp.v23.1010

Shenton, A.K., 2004, 'Strategies for ensuring trustworthiness in qualitative research projects', Education for Information 22(2), 63-75. https://doi.org/10.3233/EFI2004-22201

Smit, S., Preston, L.D. \& Hay, J., 2020, 'The development of education for learners with diverse learning needs in the South African context: A bio-ecological systems analysis', African Journal of Disability (9), 1-9. https://doi.org/10.4102/ajod. v9i0.670

Strauss, A.L. \& Corbin, J.M., 1998, Basics of qualitative research: Techniques and procedures for developing grounded theory, Sage, Thousand Oaks, CA.

Terzi, L., 2014, 'Reframing inclusive education: Educational equality as capability equality', Cambridge Journal of Education 44(4), 479-493. https://doi. org/10.1080/0305764X.2014.960911

Topkin, B., Roman, N.V. \& Mwaba, K., 2015, Attention deficit disorder (ADHD): Primary school teachers' knowledge of symptoms, treatment and managing classroom behaviour', South African Journal of Education 35(2), 1-8. https://doi. org/10.15700/saje.v35n2a988

United Nations Educational, Scientific and Cultural Organization (UNESCO), 1994 Policy guidelines on inclusion in education, UNESCO, Paris.

United Nations Educational, Scientific and Cultural Organization (UNESCO), 2009, Policy guidelines on inclusion in education, UNESCO, Paris.

Upadhyay, R., Srivastava, P., Singh, N.K. \& Poddar, S., 2016, 'Community attitude and stigma towards mental illness: A gender perspective', Journal of Psychosocia Research 11(2), 335

Villodas, M., McBurnett, K., Kaiser, N., Rooney, M. \& Pfiffner, L., 2014, 'Additive effects of parent adherence on social and behavioural outcomes of a collaborative school-home behavioural intervention for ADHD', Child Psychiatry \& Human Development 45(3), 348-360. https://doi.org/10.1007/s10578-0130405-7

Walton, E., 2018, 'Decolonising (through) inclusive education?', Educational Research for Social Change 7, 31-44. https://doi.org/10.17159/2221-4070/2018/v7i0a3

Westergard, E., 2013, 'Teacher competencies and parental cooperation', International Journal about Parents in Education 7(2), 91-99.

Xu, G., Strathearn, L., Liu, B., Yang, B. \& Bao, W., 2018, 'Twenty year trends in diagnosed attention-deficit/hyperactivity disorder among US children and adolescents, 1997-2016', JAMA Network Open 1(4), e181471. https://doi. org/10.1001/jamanetworkopen.2018.1471

Yssel, N., Engelbrecht, P., Oswald, M.M., Eloff, I. \& Swart, E., 2007 'A comparative study of parents' perceptions in South Africa and the United States', Remedial and Special Education 28(6), 356-365. https://doi.org/10.1177/07419325070280 and Spe
060501 